Family Profile No. 7, 2020

\title{
Recently Divorced Adults with Resident Minor Children, 2018
}

Author: Valerie J. Schweizer

The overall divorce rate has reached a 40-year low, and the first divorce rate has declined in recent years to 14.9 divorces per 1,000 married women (FP-19-23; FP-20-02). Many parents are among the recently divorced, and these divorced parents may have resident children. Using American Community Survey (ACS) data from 2018, we estimate whether there are minor children (either biological, stepchildren, or adopted) present in the household among recently divorced (within the last year) parents aged 18-55. Some recently divorced individuals may have nonresident children (which the ACS does not count), so these figures underestimate the overall percentage of recently divorced individuals with children. We first compare recently divorced parents to their counterparts - married parents who did not experience a divorce in the last year - and look at the age composition of resident children. We also investigate the prevalence of minor children among recently divorced individuals by race/ethnicity and education. This profile is an update to FP-16-11.

\section{Household Presence and Age of Minor Children}

- In 2018, 40\% of all recently divorced men and women reported having at least one minor child living in their household.

- Among currently married parents, $60 \%$ had at least one minor child in the household.

- Of those who had a minor child in the household, there was some age variation between the children of recently divorced parents and currently married parents.

- A majority of both recently divorced (63\%) and currently married (55\%) parents had only children between the ages of 6 and 17 (not shown).

Figure 1. Percentage of Adults 15-55 Reporting Minor Children in the Household, by Divorce Status

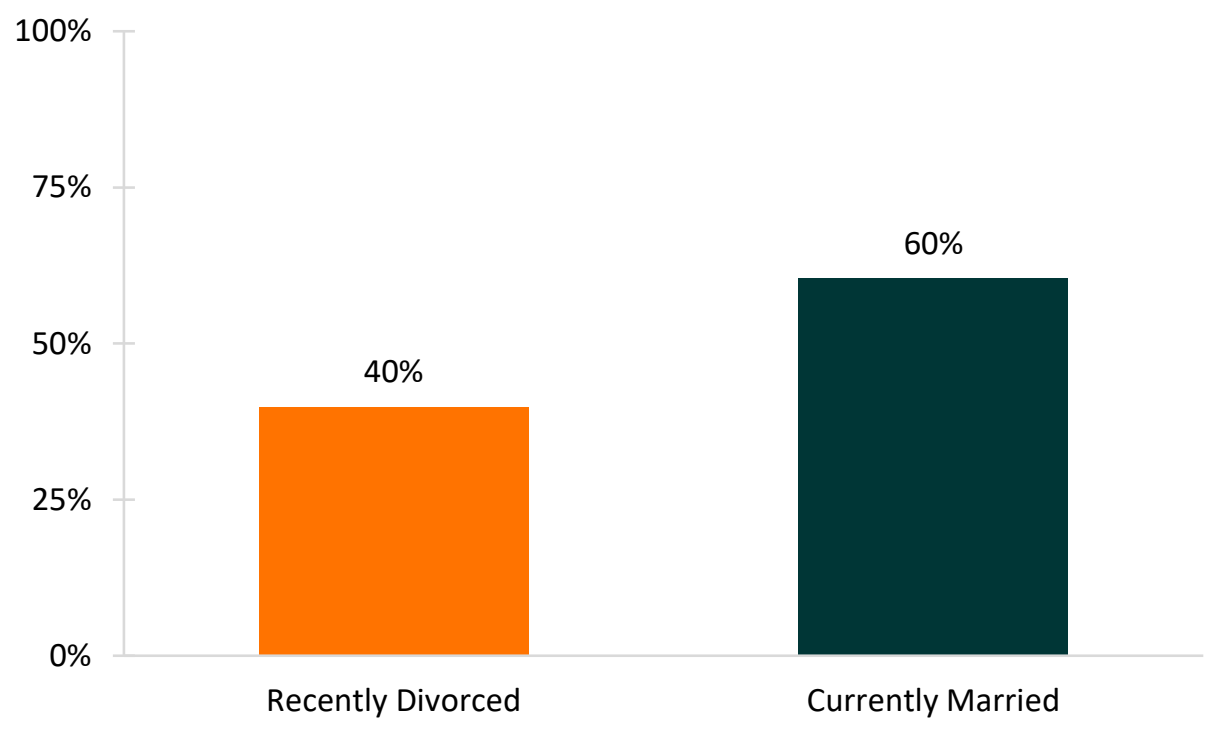

Source: NCFMR analyses of the American Community Survey 1-yr. est., 2018. 
Race and Ethnicity

Figure 2. Percentage of Recently Divorced Individuals Reporting Minor Children in the Household, by Race/Ethnicity

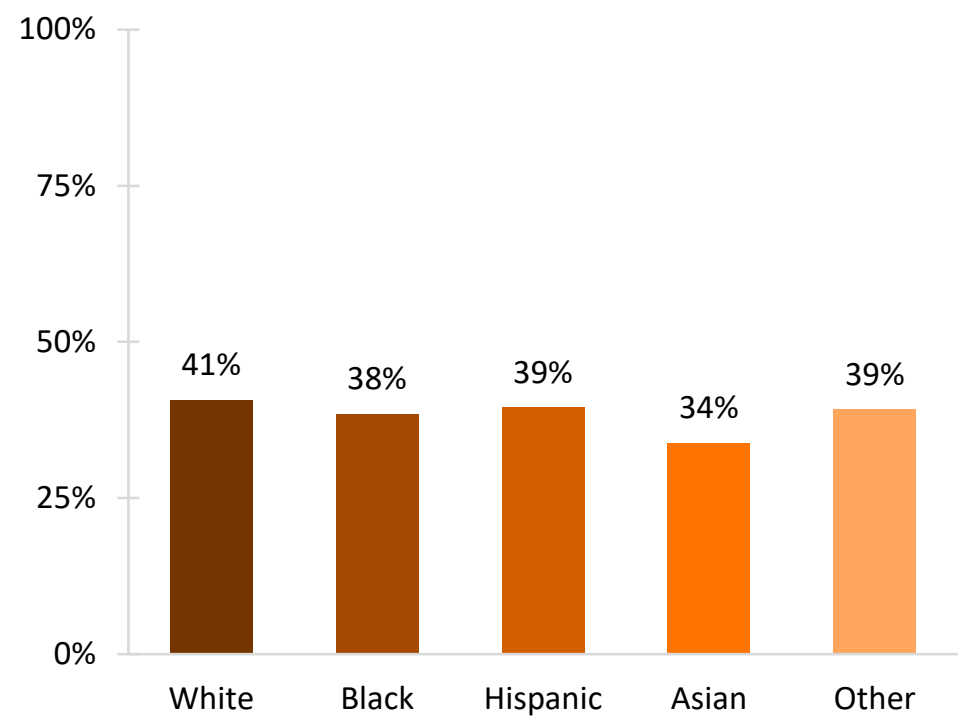

- There was minimal racial/ethnic variation among recently divorced individuals with minor children in the household.

- White recently divorced parents reported the highest prevalence of minor children in the household (41\%), while recently divorced Asian parents reported the lowest (34\%).

- Comparable shares of Black, Hispanic, and Other recently divorced individuals reported having a minor child in the household.

Source: NCFMR analyses of the American Community Survey 1-yr. est., 2018.

\section{Educational Attainment}

- There was also little variation in educational attainment among recently divorced minor parents.

○ Those with at least some college had the highest prevalence of minor children in the household (42-43\%).

- $37 \%$ of recently divorced parents with a high school education had at least one minor child in the household.

- The proportion was lowest among those with less than a high school education (34\%).
Figure 3. Percentage of Recently Divorced Individuals Reporting Minor Children in the Household, by Educational Attainment

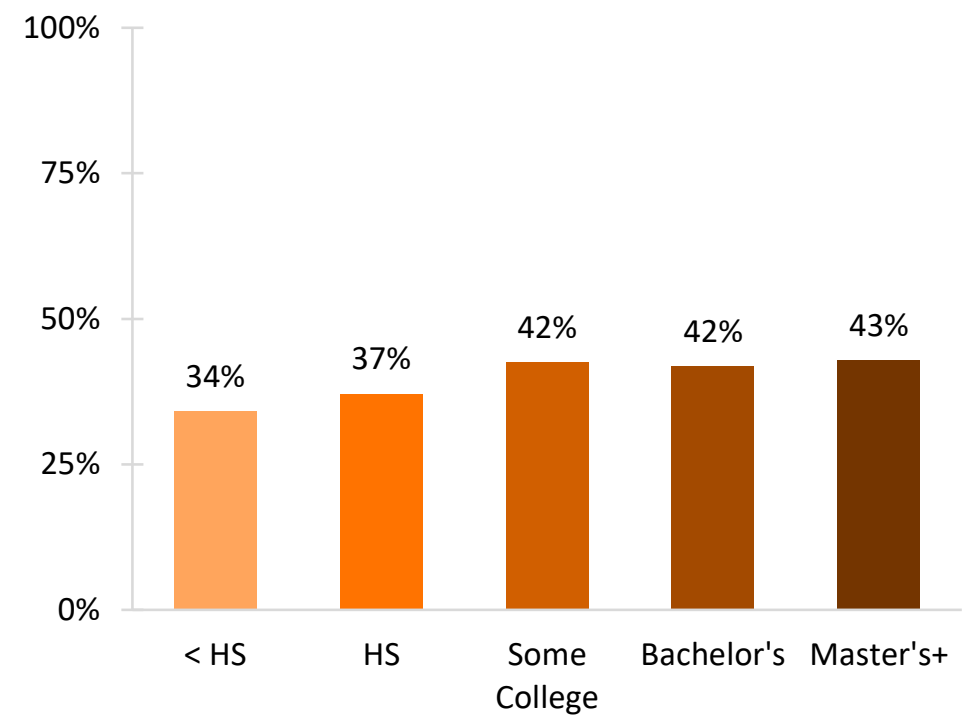

Source: NCFMR analyses of the American Community Survey 1-yr. est., 2018.

\section{References:}

Allred, C. (2019). Divorce rate in the U.S.: Geographic variation, 2018. Family Profiles, FP-19-23. Bowling Green, OH: National Center for Family \& Marriage Research. https://doi.org/10.25035/ncfmr/fp-18-23

Allred, C. \& Schweizer, V. (2020). First divorce rate in the U.S., 2018. Family Profiles, FP-20-02. Bowling Green, OH: National Center for Family \& Marriage Research. https://doi.org/10.25035/ncfmr/fp-20-02

Eickmeyer, K. J. (2016). Recently divorced adults with resident minor children. Family Profiles, FP-16-11. Bowling Green, OH: National Center for Family \& Marriage Research. https://www.bgsu.edu/ncfmr/resources/data/family-profiles/eickmeyer-recently-divorced-adults-resident-child-fp-16-11.html

\section{Suggested Citation:}

Schweizer, V. (2020). Recently divorced adults with resident minor children, 2018. Family Profiles, FP-20-07. Bowling Green, OH: National Center for Family \& Marriage Research. https://doi.org/10.25035/ncfmr/fp-20-07

BCSU. $\mid \begin{aligned} & \text { National Center for } \\ & \text { Family \& Marriage Research }\end{aligned}$ $\frac{\text { http://www.bgsu.edu/ncfmr }}{\text { ncfmr@bgsu.edu }}$ of the author(s) and should not be construed as representing the opinions or policy of any agency of the state or federal government. 